\title{
By What Means Can the Chinese Government Implement Policies to Aid in the Increase of Fertility Rate of Working Women?
}

\begin{abstract}
Kai $\mathrm{Lu}$
Rotman School of Management, University of Toronto, Toronto, Ontario M5S 3E6, Canada. Email:kai.lu@mail.utoronto.ca

Abstract

China's declining population results in a smaller future labor force and threatens the economy coupled with its aging population. To ameliorate this issue, this paper suggests that the Chinese government focus on mitigating the discrimination to female workers as well as providing more job security to workers taking parental leave to boost China's fertility rate. This allows more flexibility regarding the division of responsibility of raising a child and reduces the negative impact pregnancy can have on a worker's professional career, thus incentivizing him/her to have more children. To achieve these goals, the Chinese government should unify the disparity between paternal and maternal laws in China, use campaigns to promote a more open mindset and encourage the behavior of fathers contributing to the upbring of children, and mandate corporations to purchase parental insurances for all its workers by combining it with the basic medical insurance.
\end{abstract}

Keywords: China, Fertility, Policy Recommendations

\section{INTRODUCTION}

China is currently experiencing a declining population, with its fertility rate being 1.30 [1] which is far below the world average of 2.42 and China's replacement rate of 2.30 [2]. As the saying goes, "today's babies are tomorrow's workers" a fertility rate below the replacement rate is problematic because it not only shrinks the future labor force but it also changes the structure of a country's population as fewer young people are being born. At the same time, China also has a large aging population $(60+$ years old) which is projected to reach $28 \%$ by 2040 [3]. A low fertility rate coupled with a large aging population increases the dependency ratio of China and slows economic growth [4]. A further investigation of this problem and its potential solutions beg a closer look at China's current parental leave policies and laws against pregnancy or gender-based discrimination in employment. 
Total fertility rate in China from 1930 to $2020^{*}$

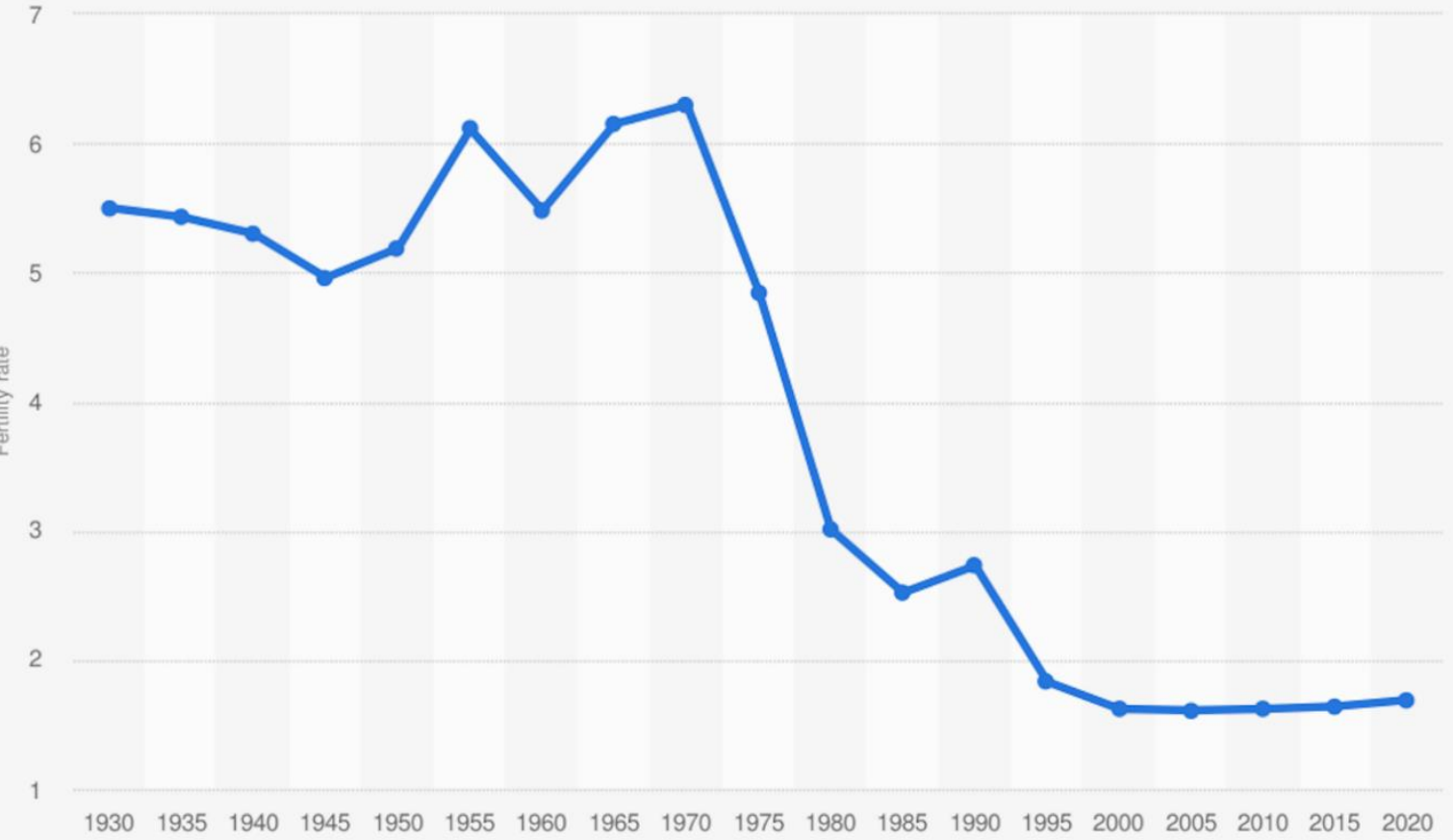

Figure 1: total fertility rate in China from 1930 to 2020 [5]

\section{Share of population aged 60 and older in China from 1950 to 2010 with forecasts until 2100}

$50 \%$

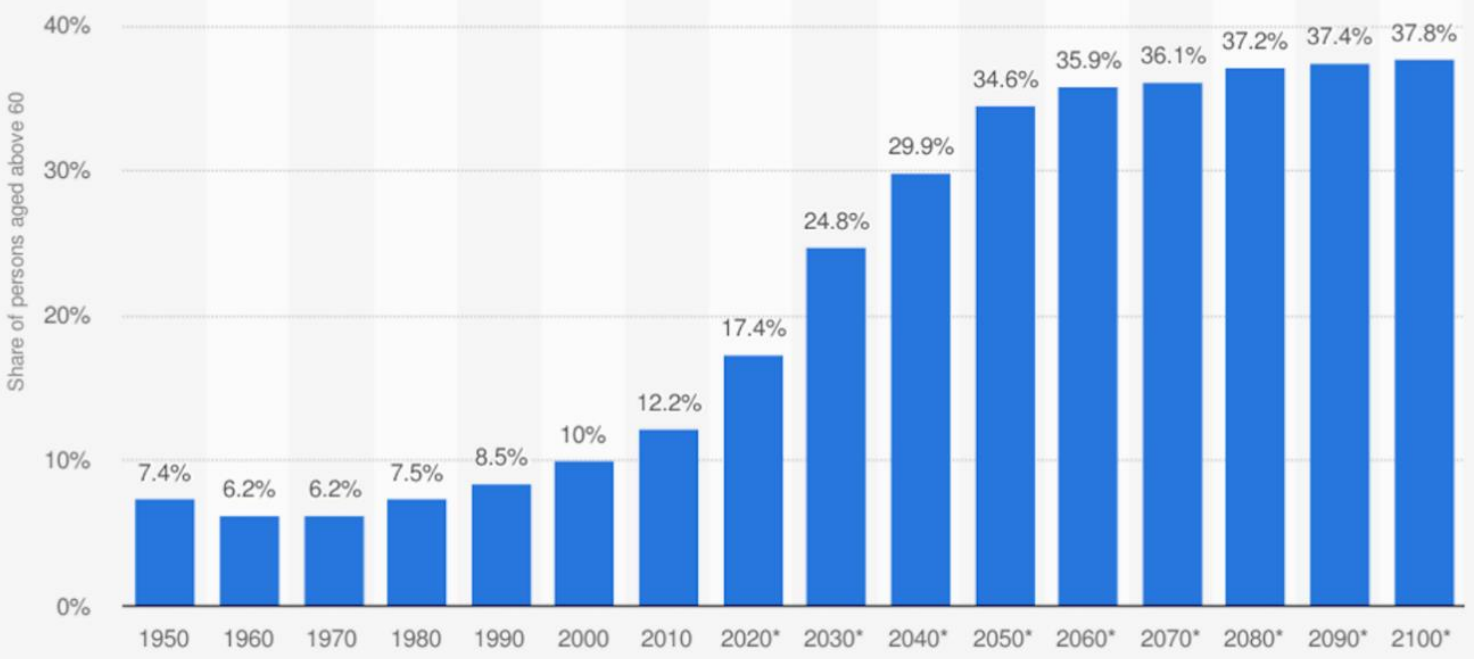

Figure 2: share of population aged 60 or older in China from 1950 to 2010 with forecasts until 2100 [6] 


\section{CURRENT POLICIES AND THEIR CONSEQUENCES}

A female employee in China is entitled to a minimum of 98 days of maternity leave with 1-3 months of additional leave depending on the region she is in, while 15 days is the standard paternity leave for male workers in most regions [7]. This significant disparity between maternity and paternity leave forces the responsibility of raising a child on females, most of whom, according to Xi'an JiaoTong University Professor Yang Xue Mei [8], "have quite inflexible jobs". "I'm planning to have one child at most because I think raising a child takes too much time investment," says Tao Jia Jia [9], a 27 years old female employee in China. Time investment isn't the only factor discouraging female workers from having children. Female employees in China are also susceptible to pregnancy-based discrimination in employment [10] and negative employment prospects related to childbearing will significantly lower fertility [11]. Although China has attempted to promote equality in employment by banning employers from using discriminatory practices against females such as requesting information regarding marriage or childbirth conditions in job applications and allowing The people's courts to accept lawsuits relating to discrimination against women in employment [12], "compensation awarded to victims is too often too small to justify going through the legal system and penalties imposed on companies too insignificant to serve as a deterrent for future violators" [10].

\section{SOLUTION AND ITS ADVANTAGES}

Working women are the main target for this paper's suggested solutions as they make up a majority $(60.4 \%)$ of China's female population [13]. Also, the children of working mothers are more likely to join the labor force as well, thus becoming a net gain to the economy [14].

This paper suggests that the Chinese government should focus on mitigating discrimination towards workers (mostly women) who are potential child-bearers in the workplace through unifying the disparities between maternity and paternity leave and providing more job security to workers taking parental leave. This allows more flexibility regarding the division of responsibility of raising children between the two parents and discourages employers from gender-based discrimination as both male and female employees are entitled to similar leave time. More flexibility as well as opportunity for the father to share the burden of raising a child with the mother can potentially increase the workers' desire to have more children, thus boosting China's fertility rate to support the large aging population and maintain economic growth. According to Sun Yat-Sen University Social Studies Department Professor Wang Jun [15], "Encouraging the father to contribute to the raising of a child will not only make the mother's life easier but also have a positive impact on the child's development, improving the quantity and quality of China's population".

\section{POLICY RECOMMENDATIONS TO MITIGATE DISCRIMINATION}

\subsection{Adopt a Shared Parental Leave System}

To close the gap between China's Maternity and Paternity leave, China should adopt a shared parental leave system where a certain amount of parental leave time is shared between the partners such as the Swedish model which allows 480 days of parental leave shared between the partners [7]. Germany passed a reform of the parental leave benefit system in line with the Swedish model in 2007 [16] and has had a steady growth in fertility rate since, but this isn't enough to correlate the Swedish model with increased fertility rate as various other policies were implemented during that time to encourage fertility [17]. However, due to the significant difference between China's current parental leave policy and the Swedish model, adopting the Swedish model may not be feasible in the short run as lengthy parental leaves are likely to decrease the productivity of businesses, especially smaller businesses [18]. It is recommended, therefore, that China adjust the parental leave policy to a 210 day shared parental leave with $100 \%$ of their salaries paid by the Maternity Insurance Fund which is already in the current parental leave policy [7] and may pursue a lengthier parental leave in the long run, allowing more adjustment time for the economy.

Although a shared parental leave discourages employers from using gender-based discrimination, employers may still use pregnancy-based discrimination where workers who already have two children are favored as they won't have more under the two-child policy [10]. However, China's current fertility rate of 1.30 means the majority of parents in China aren't choosing to have two children, and these workers who have maxed out their baby numbers become even less after the introduction of the three-child policy in May 2021. Therefore, this form of pregnancy-based discrimination shouldn't be a significant concern.

\subsection{Encourage male workers to take paternity leave and share responsibility with the mother}

An issue that may arise from a shared parental leave system is male workers refusing to take it. "most of the time the father may end up transferring all his time to the mother who will exacerbate inequality and discrimination in employment" says Yang Hui [19], a Professor at 
Women's Studies Institute of China. "This happens because the father worries about his job security as well as societal pressures," she adds. Therefore, it is recommended that China mandates a 60-day parental leave to male workers, which will be lost if not taken by them, and they can choose to transfer the rest. Also, an additional three weeks of leave time can be awarded if the male worker chooses to take more than 60 days of paternal leave.

However, mandatory leave is not a strong enough incentive under the traditional Confucian Patriarchal culture which China is deeply influenced by [20]. The government, therefore, should promote and raise awareness on gender equality in terms of the responsibility of raising a child and the benefits of mother and father equally sharing the responsibility of parenting can have on a child's cognitive development [21] to encourage male workers to be more involved in raising their child(ren) through campaigns. The government can also incorporate gender equality topics including sharing the responsibility of parenting into the school curriculum.

\subsection{Combining Maternity Insurance with basic medical insurance}

China currently mandates employers to pay maternity insurance to their workers [22] which will cover workers' salaries during their parental leave. However, some employers chose to disobey this law to avoid paying the cost of such insurance and will have to pay workers' on parental leaves from their own pockets as a result [10]. This creates a financial incentive for employers who refuse to pay maternity insurance to use gender and pregnancy-based discrimination against their workers. It is recommended that China combine Maternity Insurance with basic medical insurance, which more than $90 \%$ of Chinese workers are already covered by [23] and is heavily subsidized by the Chinese government [23], in all cities as it is already done in most cities [22].

\section{CONCLUSION}

A low fertility rate in China is a very urgent issue as it can create momentum for steady population decline in the future which will slow economic growth which becomes especially problematic with China's large aging population that exert further pressure on the government budget. By adopting a shared parental leave system, promoting male workers' involvement in raising their children, and combining maternity insurance with basic medical insurance, China is likely going to see a larger, more gender-equal population in the future.

\section{REFERENCES}

[1] Ning , Jizhe. "Main Data of the Seventh National Population Census News Release." Main Data of the Seventh National Population Census, 11 May 2021,
www.stats.gov.cn/english/PressRelease/202105/t20 210510_1817185.html.

[2] United Nations, Department of Economic and Social Affairs, Population Division (2019). World Population Prospects 2019: Data Booklet. ST/ESA/SER.A/424.

[3] World Health Organization. "Ageing and Health China." World Health Organization, World Health Organization, www.who.int/china/healthtopics/ageing.

[4] Vollset, Stein Emil, et al. "Fertility, mortality, migration, and population scenarios for 195 countries and territories from 2017 to 2100: a forecasting analysis for the Global Burden of Disease Study." The Lancet 396.10258 (2020): 1285-1306.

[5] Wu, F. (2019) 'China country note,' in Koslowski, A., Blum, S., Dobrotić, I., Macht, A. and Moss, P. (eds.) International Review of Leave Policies and Research 2019. Available at: http://www.leavenetwork.org/lp_and_r_reports/

[6]O'Neill, Aaron. "China: Fertility Rate 1930-2020." Statista, 2 Mar. 2021, https://www.statista.com/statistics/1033738/fertility -rate-china-1930-2020/.

[7]Textor, C. "China: Population Share Aged 60 and Older until 2100." Statista, 6 Apr. 2021, https://www.statista.com/statistics/251529/shareof-persons-aged-60-and-older-in-the-chinesepopulation/.

[8] Yang, X., 2021. China's Fertility Rate [Interview] (02 8 2021).

[9] Tao, J., 2021. China's Fertility Rate [Interview] (01 8 2021).

[10] Wang, Yaqiu. "“Take Maternity Leave and You'll Be Replaced." Human Rights Watch, 14 July 2021, www.hrw.org/report/2021/06/01/take-maternityleave-and-youll-be-replaced/chinas-two-childpolicy-and-workplace.

[11] Neyer, Gerda, Trude Lappegård, and Daniele Vignoli. "Gender equality and fertility: Which equality matters?." European Journal of Population/Revue européenne de Démographie 29.3 (2013): 245-272.

[12] Global Times. "China to End Workplace Gender Discrimination, Ban Employers from Asking Woman about Childbirth Status." Global Times, 22 
Feb.

2019 , https://www.globaltimes.cn/content/1139751.shtml.

[13] International Labor organization. "Labor Force Participation RATE, Female $(\%$ of Female Population Ages 15+) (Modeled ILO Estimate) China." The World Bank Data, The World Bank, 15 June 2021, data.worldbank.org/indicator/SL.TLF.CACT.FE.ZS ?locations $=\mathrm{CN}$.

[14] Ordway, Denise-Marie. "What Research Says about the Kids of Working Moms." The Journalist's Resource, 6 Aug. 2018, journalistsresource.org/economics/workingmother-employment-research/.

[15] Jun, W., 2021. China's Fertility Rate [Interview] (02 8 2021).

[16] Spiess, C. Katharina, and Katharina Wrohlich. "The parental leave benefit reform in Germany: costs and labor market outcomes of moving towards the Scandinavian model." (2006).

[17] Martin, David. “Are Family Policy Reforms to Thank for GERMANY'S Rising Birth Rates?: Dw: 29.03.2018." DW.COM, 29 Mar. 2019, www.dw.com/en/are-family-policy-reforms-tothank-for-germanys-rising-birth-rates/a-43188961.

[18] Martins , Andrew. "Should You Offer Paternity Leave?" Business News Daily, 11 Dec. 2020, www.businessnewsdaily.com/15943-paternityleave.html.

[19] Yang, H., 2021. China's Fertility Rate [Interview] (02 8 2021).

[20] Yingchun, Ji, and Zheng Zhenzhen. "China's low fertility rate from the perspective of gender and development." Social Sciences in China 41.4 (2020): 169-184.

[21] Keizer, Renske, et al. "The influence of fathers and mothers equally sharing childcare responsibilities on children's cognitive development from early childhood to school age: An overlooked mechanism in the intergenerational transmission of (dis) advantages?." European Sociological Review 36.1 (2020): 1-15.

[22] L\&E Global. "Employee Benefits in China." L\&E Global Knowledge Centre, 16 Feb. 2021, https://knowledge.leglobal.org/social-security-inchina/.

[23] Pattinson, Tom. "How Does CHINA'S Healthcare System Actually Work?: Focus - CHINA BRITAIN Business Council." Focus, 27 Aug. 2020, focus.cbbc.org/how-chinas-healthcare-system-
actually-works/\#.YQyV45NKi3I.

[24] Pan, Li, and Jianguo Xu. "Housing price and fertility rate." China Economic Journal 5.2-3 (2012): 97-111.

[25] Hankins, Frank H. "German Policies for Increasing Births.” American Journal of Sociology, vol. 42, no. 5, 1937, pp. 630-652. JSTOR, www.jstor.org/stable/2767759. Accessed 5 Aug. 2021.

[26] Chen, Wei, and Yong-ai Jin. "Gaps between fertility intentions and fertility outcomes in China: Patterns and determinants." Population Journal 33.2 (2011): $3-13$. 